\title{
Care practices and traditional beliefs related to neonatal jaundice in northern Vietnam: a population-based, cross-sectional descriptive study
}

\author{
Loc T Le ${ }^{1 *}$, John Colin Partridge ${ }^{1}$, Bich H Tran², Vui T Le ${ }^{2}$, Tuan K Duong ${ }^{2}$, Ha T Nguyen ${ }^{2}$ and Thomas B Newman ${ }^{1,3}$
}

\begin{abstract}
Background: The National Hospital of Pediatrics in Vietnam performed >200 exchange transfusions annually (2006-08), often on infants presenting encephalopathic from lower-level hospitals. As factors delaying care-seeking are not known, we sought to study care practices and traditional beliefs relating to neonatal jaundice in northern Vietnam.

Methods: We conducted a prospective, cross-sectional, population-based, descriptive study from November 2008 through February 2010. We prospectively identified mothers of newborns through an on-going regional cohort study. Trained research assistants administered a 78-item questionnaire to mothers during home visits 14-28 days after birth except those we could not contact or whose babies remained hospitalized at 28 days.

Results: We enrolled 979 mothers; $99 \%$ delivered at a health facility. Infants were discharged at a median age of 1.35 days. Only $11 \%$ received jaundice education; only $27 \%$ thought jaundice could be harmful. During the first week, $77 \%$ of newborns were kept in dark rooms. Only 2.5\% had routine follow-up before 14 days. Among 118 mothers who were worried by their infant's jaundice but did not seek care, $40 \%$ held non-medical beliefs about its cause or used traditional therapies instead of seeking care. Phototherapy was uncommon: $6(0.6 \%)$ were treated before discharge and $3(0.3 \%)$ on readmission. However, there were no exchange transfusions, kernicterus cases, or deaths.

Conclusions: Early discharge without follow-up, low maternal knowledge, cultural practices, and use of traditional treatments may limit or delay detection or care-seeking for jaundice. However, in spite of the high prevalence of these practices and the low frequency of treatment, no bad outcomes were seen in this study of nearly 1,000 newborns.
\end{abstract}

Keywords: Hyperbilirubinemia, Newborn, Care-seeking behavior, Vietnam, Traditional medicine, Phototherapy

\section{Background}

Severe hyperbilirubinemia and kernicterus are rare in developed countries where bilirubin screening, blood typing, phototherapy equipment, and Rh immune globulin are available. In developing countries where these preventive therapeutic interventions are often unavailable, severe hyperbilirubinemia causes significant morbidity and mortality [1-14]. In Vietnam, the lack of blood type testing, Rh immune globulin and accessible phototherapy may in part explain the frequent use of exchange transfusion for the treatment of severe hyperbilirubinemia $[15,16]$.

\footnotetext{
* Correspondence: loctle@gmail.com

'Department of Pediatrics, University of California, San Francisco, Box 0748,

533 Parnassus Ave, U585, San Francisco, CA 94143, USA

Full list of author information is available at the end of the article
}

At the National Hospital of Pediatrics (NHP), the tertiary referral hospital for $>31$ million people in northern Vietnam, 18\% of neonatal admissions in 2002 were for hyperbilirubinemia, $22 \%$ of babies admitted for jaundice from 2003-05 underwent exchange transfusion, and an average of 207 exchange transfusions were performed yearly in 2006-08 [15].

A case series we conducted of infants undergoing exchange transfusion at the NHP suggested that delays in diagnosis and treatment contributed significantly to the use of exchange transfusion to treat severe hyperbilirubinemia [16]. That study, however, provided no quantitative data about the barriers causing delays in care-seeking among those not receiving exchange transfusion, and hence could not quantify their importance as risk factors for severe hyperbilirubinemia. We speculated 
that low parental knowledge of jaundice, traditional non-medical beliefs about causes and treatment, wrong medical advice, and inefficient transport procedures likely contributed to delayed care-seeking in some infants. In this study, we describe the prevalence of community care practices and traditional beliefs that may contribute to delayed presentation with severe hyperbilirubinemia and the frequency of phototherapy use.

\section{Methods}

We conducted a prospective, cross-sectional, descriptive population-based study at CHILILAB, a demographic and epidemiologic surveillance system established in 2003 by the Hanoi School of Public Health (HSPH) for public health and health policy research, from November 2008 through February 2010. CHILILAB is a member of the INDEPTH Network, an international network of field labs in 20 nations around the world that supports the development of longitudinal sites for health and social science research as well as intervention impact assessments. Located in Chi Linh District, Hai Duong Province (55 kilometers northeast of Hanoi), CHILILAB is comprised of 4 rural communes and 3 towns, with a study population of approximately 57,000 inhabitants from about 18,000 households. The entire district contains 17 communes and 3 towns, with a population of 142,278 (2010) [17].

The district public health care system consists of 1 district hospital, a regional health clinic, and 20 commune health stations. Commune health stations have nurse midwives who attend low risk vaginal deliveries while district hospitals have physicians who are able to perform $\mathrm{C}$-sections. High risk deliveries are transferred to provincial or national hospitals. Sick neonates are usually transferred to the nearest neonatal intensive care unit at the provincial hospital 34 kilometers away or to the National Hospital of Pediatrics in Hanoi. Rapidly urbanizing and industrializing, Chi Linh District mirrors the socio-economic and demographic changes occurring throughout Vietnam [17].

We obtained research approval from both the HSPH Institutional Ethical Review Board (Approval \#057/2008/ YTCC-HD3) and University of California, San Francisco, Committee for Human Research (Approval \#H6316833205-01) in accordance with the Declaration of Helsinki. The study was approved locally by the Chi Linh District People's Committee and district health officials.

We developed a questionnaire with input from Vietnamese physicians and public health faculty at the Hanoi School of Public Health to evaluate maternal knowledge of jaundice, to assess community newborn care practices that may affect jaundice detection and care-seeking behavior, and to determine the incidence of phototherapy. We then conducted a training session for the research assistants, reviewing the questionnaire and interview techniques before piloting the study for
2 weeks. Afterwards, we reconvened to address any problems and to revise the questionnaire with input from the research assistants, all of whom live in the community and have understanding of local care practices, before commencing the study.

We identified all expectant mothers through weekly telephone contact at commune health stations and the Chi Linh District Hospital where they were receiving prenatal care. All pregnant women are allowed a limited number of free prenatal care visits through the socialized government health care system which allows identification of pregnant mothers. Through prenatal and delivery records, we obtained their estimated delivery dates, and identified deliveries that occurred within the prior week. Mothers who were transferred to higher level hospitals due to complicated deliveries or electively delivered outside of the catchment area were captured during home visits conducted after their estimated date of delivery. The research assistants conducted home visits at 14-28 days after birth, and travelled on foot, bicycle, or motorcycle to reach the households. With these measures, we believe that we were able to identify nearly all and enroll most live births.

All consenting mothers of live-born infants in the CHILILAB surveillance area were included except those we could not contact or whose babies remained hospitalized at 28 days. After obtaining informed consent, the research assistants administered a 78-item questionnaire to the mother (Additional files 1 and 2). The questionnaire asked household demographic information, birth history, birth complications, presence of cephalohematoma, length of stay, newborn feeding, care practices, exposure or avoidance of sunlight, beliefs about effects of sunlight, use of traditional remedies, herbal medications, Chinese medicines, umbilical cord care, home environment, maternal knowledge of jaundice, maternal recognition and concern about jaundice, sibling history of jaundice, care seeking for jaundice, newborn follow-up care, symptoms of kernicterus, newborn re-hospitalization, phototherapy, and treatment history. We asked whether cost, distance, bad weather, poor perception of health providers, "baby was too young to take outside", and lack of transportation were barriers to care. Mothers could choose more than one barrier and also could give an open response for other perceived barriers. Socio-economic data were extracted from the existing CHILILAB database, and class was categorized according to a standardized assessment of household wealth based upon possessions, home structure, and utilities.

We entered data into Microsoft Access, and then exported to STATA 11 (Statacorp, College Station, TX) for analysis. We used descriptive statistics, t-tests, chisquared tests, and Wilcoxon rank sum tests to measure various associations with receiving phototherapy. 


\section{Results}

\section{Demographics}

Based upon Chi Linh District's crude birth rate of 15.6 per 1,000 people [17], we expected approximately 1,186 births in the CHILILAB's catchment population of 57,000 over the 16 month study period. We identified 1,058 total births, of whom 61 (5.8\%) were lost to follow-up, and 10 $(0.9 \%)$ were excluded for hospitalization $>28$ days. Eight (0.8\%) mothers declined participation, leaving 979 (93\%) eligible infants with mothers consenting for participation. Over half resided in rural areas. Economic status of households was distributed evenly across economic quintiles. The most common head-of-household occupations were farming (28\%), small business owner/trade worker (21\%), factory worker/laborer (21\%), and government official (10\%). The vast majority (96\%) of mothers had attended secondary (middle) school or higher. Illiteracy is low (0.5\%) compared to the worst affected communes in CHILILAB (2-4\%), [18] (Table 1) and compared to overall adult illiteracy in Vietnam (6.6\%) (2008-12) [19].

\section{Hospitalization and jaundice treatment}

We obtained information on birth location, delivery history, hospitalization course, maternal and neonatal complications, and newborn readmissions within 14 days of delivery. Most (76\%) delivered locally at either commune health stations or the district hospital, and $<1 \%$ delivered at home. The median hospital stay after birth was 1.35 days. Almost 3\% $(n=28)$ of infants had perinatal complications (by maternal report); the most common and medically significant were birth asphyxia, jaundice, respiratory distress/apnea, prematurity/small for gestational age, infection, and meconium/amniotic fluid aspiration. Four percent $(n=40)$ had birth weight $<2,500$ grams. Of the 924 mothers who knew the gestational age of their infants, $1 \%(\mathrm{n}=10)$ were $32-33$ weeks gestation, and $14 \%(\mathrm{n}=130)$ were $34-36$ weeks gestation. Because surfactant and adequate total peripheral nutrition were not yet routinely available at the National Hospital of Pediatrics at the time of this study, premature infants born $<32$ weeks gestation have variable survival, and those $<28$ weeks gestation typically do not survive due to limitations in neonatal care. Surviving infants $<32$ weeks typically would be hospitalized beyond 28 days, and would not be included in our sample. The readmission rate was $0.9 \%(n=9)$ (Table 2), with 3 for pneumonia, 1 for prematurity, pneumonia and jaundice, 1 for brain hemorrhage, apnea and jaundice, 1 for gastrointestinal infection and jaundice, 1 for emesis, 1 for fever, and 1 for umbilical bleeding.

For infants who had an extended birth hospitalization or were readmitted, we asked if they received phototherapy or exchange transfusion and their outcome. Overall, 9 $(0.9 \%)$ received phototherapy during the neonatal period.
Table 1 Demographic \& socio-economic status

\begin{tabular}{|c|c|c|}
\hline \multicolumn{3}{|l|}{ Demographic information, $\mathrm{N}=979$} \\
\hline Maternal Age (years) (mean $\pm S D$, range) & $26.5 \pm 4.9$ & $(16,46)$ \\
\hline Gravity (mean $\pm S D$, range) & $1.8 \pm 1.0$ & $(1,6)$ \\
\hline Parity (mean $\pm S D$, range) & $1.6 \pm 0.7$ & $(1,6)$ \\
\hline Rural residence $(n, \%)^{*}$ & 496 & $54 \%$ \\
\hline Household economic Quintile, N=913* & $\mathrm{N}$ & $\%$ \\
\hline Lowest & 161 & 18 \\
\hline Below average & 208 & 23 \\
\hline Average & 231 & 25 \\
\hline Above average & 175 & 19 \\
\hline Highest & 138 & 15 \\
\hline Total & 913 & 100 \\
\hline Occupation of head of household, $\mathrm{N}=781^{*}$ & $\mathrm{n}$ & $\%$ \\
\hline Farmer & 222 & 28 \\
\hline Business owner/trade worker & 164 & 21 \\
\hline Factory worker/laborer & 163 & 21 \\
\hline Government official & 81 & 10 \\
\hline Handicraft & 62 & 8 \\
\hline In vocational training & 53 & 7 \\
\hline Unemployed & 17 & 2 \\
\hline Student & 3 & $<1$ \\
\hline Housewife & 3 & $<1$ \\
\hline Retired & 2 & $<1$ \\
\hline Elderly & 1 & $<1$ \\
\hline Other & 10 & 1 \\
\hline Total & 781 & 100 \\
\hline Education level, $\mathrm{N}=781^{*}$ & $\mathbf{n}$ & $\%$ \\
\hline Illiterate & 4 & 0.5 \\
\hline Primary school & 27 & 3 \\
\hline Secondary school & 378 & 48 \\
\hline High school & 205 & 26 \\
\hline Vocational school & 69 & 9 \\
\hline College & 30 & 4 \\
\hline University & 63 & 8 \\
\hline Post-graduate & 5 & 0.6 \\
\hline Total & 781 & 100 \\
\hline
\end{tabular}

${ }^{*}$ Extracted from CHILILAB database. Data available on fewer subjects due to migration between periods of household assessment.

Six $(0.6 \%)$ received phototherapy during the birth hospitalization. Three $(0.3 \%)$ were readmitted for jaundice with co-morbidities of pneumonia, gastrointestinal infection, or apnea due to brain hemorrhage. There were no readmissions for isolated hyperbilirubinemia, no exchange transfusions, kernicterus cases, or deaths. All sick newborns were transferred to provincial or national hospitals for levels of care that could not be provided at the district 
Table 2 Birth history, complications \& hospitalizations

\begin{tabular}{lcc}
\hline Birth location, $\mathbf{N}=\mathbf{9 7 9}$ & $\mathbf{n}$ & $\mathbf{\%}$ \\
\hline Commune health station & 180 & 18 \\
District hospital & 561 & 57 \\
Provincial hospital & 189 & 19 \\
Private clinic & 6 & $<1$ \\
Home & 9 & $<1$ \\
Other hospital & 34 & 4
\end{tabular}

Birth clinical history, $\mathrm{N}=\mathbf{9 7 9}$

\begin{tabular}{|c|c|c|}
\hline Cesarean section delivery $(n, \%)$ & 157 & 16 \\
\hline Male newborn $(n, \%)$ & 508 & 52 \\
\hline Birth weight (grams)(mean $\pm S D$, range) & $3132 \pm 416$ & $(1400,5000)$ \\
\hline $\begin{array}{l}\text { Estimated Gestational Age (weeks) } \\
\text { (mean } \pm \mathrm{SD} \text {, range) }\end{array}$ & $38.9 \pm 1.6$ & $(32,44)$ \\
\hline Length of stay (median days) & 1.35 & - \\
\hline Maternal complications during childbirth $(n, \%)$ & 46 & 5 \\
\hline $\begin{array}{l}\text { Infant complications during birth or } \\
\text { birth hospitalization }(n, \%)\end{array}$ & 28 & 3 \\
\hline Cephalohematoma (n,\%) & 23 & 2 \\
\hline $\begin{array}{l}\text { Infant perinatal complications, } \mathbf{N}=\mathbf{2 8} \\
\text { (excludes readmissions) }\end{array}$ & $\mathbf{n}$ & $\%$ \\
\hline Asphyxia & 4 & 14 \\
\hline Jaundice & 3 & 11 \\
\hline Respiratory distress/apnea & 3 & 11 \\
\hline Prematurity/small for gestational age & 3 & 11 \\
\hline Eye discharge & 3 & 11 \\
\hline Infection & 2 & 7 \\
\hline Cephalohematoma & 2 & 7 \\
\hline Separated sutures & 2 & 7 \\
\hline Meconium/amniotic fluid aspiration & 2 & 7 \\
\hline No urination & 1 & 4 \\
\hline Poor feeding & 1 & 4 \\
\hline Rash & 1 & 4 \\
\hline Don't know & 1 & 4 \\
\hline Hospitalization \& treatments, N = 979 & $\mathbf{n}$ & $\%$ \\
\hline Birth hospitalization for newborn illness & 10 & 1 \\
\hline Readmissions & 9 & 0.9 \\
\hline Phototherapy during birth hospitalization & 6 & 0.6 \\
\hline Phototherapy during readmission & 3 & 0.3 \\
\hline $\begin{array}{l}\text { Phototherapy during birth hospitalization or } \\
\text { with readmission }\end{array}$ & 9 & 0.9 \\
\hline $\begin{array}{l}\text { Exchange transfusion during birth } \\
\text { hospitalization or readmission }\end{array}$ & 0 & 0 \\
\hline Deaths & 0 & 0 \\
\hline
\end{tabular}

hospital or commune health centers. We did not have access to bilirubin or other laboratory measurements for sick infants treated at hospitals outside of Chi Linh.

\section{Care practices, risk factors, and beliefs}

The majority of women initially breast- and formula-fed their infants while waiting for their breast milk to come in. After the first week, however, the vast majority exclusively breast-fed. Exclusive formula feeding was rare. Mothball use, a possible trigger for hemolysis in newborns with G6PD deficiency, was reported by 43 mothers (4\%). Families commonly avoided exposure of their newborns to direct sunlight (88\%) and kept their newborns in dark rooms during the first 7 days (77\%). When asked about the effects of sunlight on newborns, 33\% ( $n=320)$ thought sunlight was harmful of whom 171 thought it damaged the skin and/or eyes, 142 believed newborns were "too young/weak" and "would get sick" if exposed, and 2 thought it caused congestion (Table 3). We assessed

Table 3 Feeding, home environment, beliefs, care practices, \& barriers to care, $\mathbf{N}=\mathbf{9 7 9}$

\begin{tabular}{lcc}
\hline Feedings during first $\mathbf{3}$ days & $\mathbf{n}$ & $\mathbf{\%}$ \\
\hline Exclusively breastfed & 279 & 28 \\
Breast and formula & 671 & 69 \\
Exclusively formula fed & 26 & 3 \\
Breast milk and rice water & 2 & $<1$ \\
Breast milk and sugar water & 1 & $<1$ \\
\hline Feedings after 7 days & & \\
\hline Exclusively breast milk & 751 & 77 \\
Both breast milk \& formula & 223 & 23 \\
Exclusively Formula Fed & 5 & $<1$ \\
\hline Home environment & $\mathbf{n}$ & $\%$ \\
\hline Used mothballs in the home & 43 & 4 \\
Avoided newborn exposure to sunlight & 864 & 88 \\
Kept newborn in dark, enclosed room & 750 & 77 \\
\hline Beliefs of effects of sunlight & $\mathbf{n}$ & $\%$ \\
\hline Harmful & 320 & 33 \\
Beneficial & 267 & 27 \\
Neither harmful or beneficial & 17 & 2 \\
Don't know & 375 & 38 \\
\hline Traditional newborn care practices & $\mathbf{n}$ & $\%$ \\
\hline Used traditional, herbal, or over-the counter & 164 & 17 \\
medication during 1st week & 30 & 3 \\
Used herbs to treat jaundice & 1 & 0.1 \\
\hline Peraped off white oral papules "lanh" to treat jaundice & $\mathbf{n}$ & $\%$ \\
\hline Cost & 171 & 17 \\
Distance to care & 77 & 8 \\
\hline Bad weather & 76 & 8 \\
\hline
\end{tabular}


maternal knowledge of jaundice and found that less than half had ever heard of newborn jaundice, and only $27 \%$ thought that jaundice could potentially be harmful. Only $11 \%$ received teaching on jaundice after birth (Table 4).

We inquired about the home use of traditional, herbal, or over-the-counter treatments, as these might delay care-seeking behavior and newborn follow-up care. One-hundred sixty-four (17\%) mothers reported using traditional, herbal, or over-the-counter treatments for newborn problems during the first week. Thirty (3\%) used herbal remedies to treat jaundice. Although cost was the most commonly reported potential barrier to care $(17 \%)$, the majority reported none (Table 3$)$. Routine well-baby follow-up care before 14 days was rare $(2.5 \%)$; $6 \%$ of mothers sought newborn care for medical concerns during the first 2 weeks after birth (Table 4).

Table 4 Care-seeking behavior \& jaundice knowledge

\begin{tabular}{lcc}
\hline Follow-up newborn care, $\mathbf{N}=\mathbf{9 7 9}$ & $\mathbf{n}$ & $\mathbf{\%}$ \\
\hline Sought routine, well-baby care during first 2 weeks & 24 & 2 \\
Sought care for medical concerns during first 2 weeks & 60 & 6 \\
\hline Knowledge \& recognition of jaundice, $\mathbf{N}=\mathbf{9 7 9}$ & $\mathbf{n}$ & $\mathbf{\%}$ \\
\hline Had any knowledge of jaundice prior to delivery & 439 & 45 \\
Had knowledge that jaundice can be harmful & 261 & 27 \\
Received jaundice education from health providers after birth & 105 & 11 \\
Infant appeared jaundiced during first week & 206 & 21 \\
\hline Did you worry about the jaundice and seek care? N= 206 & $\mathbf{n}$ & $\%$ \\
\hline Worried, sought medical care & 22 & 11 \\
Not worried, did not seek medical care & 66 & 32 \\
Worried, but did not seek medical care & 118 & 57 \\
\hline Reason for not seeking care for jaundice, N = 118 & $\mathbf{n}$ & $\%$ \\
\hline Physiologic jaundice, self-limited & 45 & 38 \\
Caused by lanh & 21 & 18 \\
Caused by separation of sutures/fontanelle & 20 & 17 \\
Caused by both lanh and separation of sutures/fontanelle & 1 & $<1$ \\
Still hospitalized & 8 & 7 \\
Not severe, monitored at home & 6 & 5 \\
Used herbal bath & 2 & 2 \\
Believed once skin exfoliates, jaundice will resolve & 2 & 2 \\
Weather too cold & 2 & 2 \\
Brought to traditional healer & 1 & $<1$ \\
Placed infant in the sun & 1 & $<1$ \\
Only recently became jaundiced & 1 & $<1$ \\
Asked advice from a physician & 1 & $<1$ \\
Was too busy & 1 & $<1$ \\
Was advised by people not to worry & 1 & $<1$ \\
Normal to have skin color changes & 1 & $<1$ \\
Don't know, no response & & 3 \\
\hline
\end{tabular}

Of the 206 mothers who thought their infants appeared jaundiced after birth ("vang da" - translated literally as "yellow skin"), we asked if they were worried or sought care to assess their degree of concern and understand care-seeking behaviour. Thirty-two percent $(n=66)$ were not worried and did not seek care; $11 \%(\mathrm{n}=22)$ were worried and sought care; $57 \%(\mathrm{n}=118)$ were worried, but did not seek care. Of the 118 mothers who were worried but had not sought care, we inquired why they had not done so. Forty percent $(n=47)$ offered nonmedical explanations for the cause of jaundice or treated it with traditional or herbal therapies at home. Responses of these 47 mothers included "separation/ widening of skull sutures and fontanel", "treated with herbal bath", "brought to traditional healer", "would resolve once skin peeled," and "lanh", white oral lesions that we suspect was thrush (Table 4).

We evaluated for associations between receiving phototherapy and various risk factors but could not make any conclusions due to limited power with only 9 infants receiving phototherapy.

\section{Discussion}

This population-based, cross-sectional study of nearly 1,000 infants found a high rate of beliefs and practices that might put babies at risk for severe jaundice, but little evidence of severe hyperbilirubinemia or acute bilirubin encephalopathy in contrast to the high numbers of exchange transfusion performed at the NHP. Only 9 $(0.9 \%)$ received phototherapy, $6(0.6 \%)$ of which were during birth hospitalization, and $3(0.3 \%)$ were readmissions. The readmission rate was lower than expected based on U.S. studies in which Asian newborns have higher risk [20-22] and where readmission rates for phototherapy for all races combined ranged between 0.45-3\% [20,21,23-25]. Rates of readmission were further reduced in 2 studies to $0.43 \%$ and $0.18 \%$ after the implementation of routine bilirubin screening prior to discharge [24,25]. Pre-discharge bilirubin screening and phototherapy, however, were not available in this community, and therefore, cannot explain the low rate of readmission for jaundice.

The absence of exchange transfusion or kernicterus was not surprising because our study was not designed nor powered to detect them. We conservatively estimated that there was 1 exchange transfusion per 2,545 births in northern Vietnam based upon an NHP catchment population of 31 million, crude national birth rate of 17.0 per 1,000 people (2007-09) [26], and average of 207 exchange transfusions performed yearly at the NHP (assuming exchange transfusions were performed exclusively at the NHP). However, we were expecting to find more cases of infants undergoing phototherapy and possibly detect cases of acute bilirubin encephalopathy but found none. 
Selection and referral bias may have contributed to these unexpectedly low numbers. Our death rate was zero, and rate of birth complication was low, suggesting a relatively healthy newborn population compared to studies at the NHP. We excluded infants who remained hospitalized after 28 days, which meant premature infants $<32$ weeks gestation or other sick newborns with prolonged hospitalizations, who were at higher risk for hyperbilirubinemia, would have been excluded. A study of 615 newborns admitted for hyperbilirubinemia at the NHP (2003-05) found that 72\% were low birth weight $(<2500 \mathrm{~g}), 64 \%$ were premature ( $\leq 36$ weeks), $10 \%$ had infection, $11 \%$ had birth asphyxia, and $17 \%$ had set-up for ABO-incompatibility [15]. Our case-series of 20 infants transferred to the NHP who underwent exchange transfusion (2008-2009) also showed that they were a high risk group. Seventy percent were transferred during birth hospitalization with most having co-morbidities of low birth weight, prematurity, infection, or Coombs + hemolysis. Half $(n=10)$ were delivered at tertiary centers (provincial or national hospitals) which selected for a higher risk population. Only 30\% were readmissions from home [16]. Both selection and referral bias may explain the paradox of high numbers of exchange transfusion and acute bilirubin encephalopathy at the NHP but low rates of phototherapy and rarity of complications of hyperbilirubinemia in a population-based study.

Another explanation for low rates of phototherapy may be that hyperbilirubinemia went unnoticed, undetected, or untreated. Early discharge, lack of follow-up, and low parental knowledge of jaundice leading to decreased care-seeking may all contribute to lack of detection or treatment. Common cultural practices such as keeping infants in dark rooms during the first week after birth may also hinder jaundice detection at home, causing under-reporting. Because we used maternal reporting to estimate the incidence of jaundice without information from a medical assessment, clinical jaundice may have been under-estimated. Among mothers who reported their infant appeared jaundiced, many were not concerned, did not seek care, or used traditional therapies in lieu of care-seeking. It is possible that many infants became severely jaundiced but were not identified medically, and that we did not detect any bad outcomes because we did not have long-term follow-up which might have detected hearing loss or cerebral palsy, the long-term complications of untreated acute bilirubin encephalopathy. The lack of long-term follow-up is one of the main limitations of this study. Lastly, the common use of formula supplementation during the first week of life may have been protective $[27,28]$.

Concurrent, on-going efforts by the government and NGOs to implement phototherapy at provincial hospitals may have confounded our results by decreasing the incidence of hyperbilirubinemia and kernicterus during our study. The East Meets West Foundation started distributing LED phototherapy and supported courses on basic newborn care, including jaundice management, to 136 hospitals in Vietnam from 2007-09. Jaundice admissions to the NHP dropped yearly from 865 in 2008 to 509 in 2010. Kernicterus cases, however, remained unchanged between 2008 ( $n=87$ ) and $2010(n=81)$, and only dropped significantly in $2011(n=25$, Jan-Sep) after the initiation of intensive jaundice workshops [29]. Although we cannot exclude this confounder, we believe it was unlikely that our low rates of phototherapy was an outcome of this intervention because the most dramatic changes in referrals for jaundice and kernicterus to the NHP occurred in 2011 after the conclusion of our data collection. Chi Linh District Hospital did not receive equipment or training during the study period. In addition, we would have expected increased utilization of phototherapy.

Although we were unable to determine the population incidence of hyperbilirubinemia, our study, nevertheless, contributes to understanding of perceptions of jaundice, care-seeking behavior for jaundice, and barriers to care. Our data could be used to develop educational interventions to dispel myths and improve care-seeking. Traditional, non-medical beliefs about the causes of jaundice and the use of traditional remedies in lieu of care-seeking were prevalent. Some mothers believed cranial suture diastases could cause jaundice and would treat the diastases and jaundice with an herb (typically burning the "ngai" herb and exposing the infant to the ashes or smoke). The association between jaundice and cranial suture diastasis may have arisen due to both being caused by intracranial hemorrhage which is frequent in Vietnam due to lack of vitamin K prophylaxis [30]. Others believed jaundice was caused by "lanh". These lesions reportedly developed after the first few days of life and were believed to be associated with jaundice and poor feeding. Mothers said that jaundice would resolve and feeding improve after they scraped off the "lanh". The perceived association between the improvement in jaundice with treatment of cranial suture diastasis or removal of "lanh" may just be a coincidental temporal relationship with the peaking of physiologic jaundice at 3-5 days before spontaneous resolution. However, for those cases that progress to pathologic hyperbilirubinemia, these traditional practices may have caused false reassurance, contribute to decreased or delayed careseeking, and may contribute to increased risk for severe hyperbilirubinemia. The common and widespread use of traditional medicine, including herbal therapies for jaundice, has been previously reported in northern Vietnam and suggests that such therapies competed with evidence-based treatments [31]. Traditional medicine in the newborn also has been described across many cultures, sometimes causing harm, delaying 
care-seeking [32-35], or increasing bilirubin admission levels [32].

We found that, overall, access to care was good, and there were few reported barriers except cost. Nearly all mothers delivered at a health facility, and $<1 \%$ delivered at home indicating that access to attended deliveries was not a problem. Few reported that distance, weather, and lack of transportation were potential barriers even though the primary mode of transportation is by motorcycle, and winters in northern Vietnam can be cold and rainy. Cost (17\%) was the most frequently cited barrier to seeking newborn care, a finding previously reported in Vietnam [36]. A government initiative to improve access to care and decrease cost for its most vulnerable populations led to the implementation of universal, free national health insurance for children $<6$ years in 2005 [37]. However, this insurance remains underutilized, especially among rural populations, and the burden of out-of-pocket expenses remains high due to incomplete coverage [37-39]. Informal payments to caregivers, a prevalent practice, may add hidden costs and further deter care-seeking [40].

Maternal education may be a relatively simple and feasible approach to improve detection and increase care-seeking to prevent missed cases of hyperbilirubinemia in the community. High rates of maternal literacy and good availability of care may allow for the development of standardized education modules conducted either prenatally or post-partum. Health care providers can teach mothers about jaundice, dispel erroneous beliefs, instruct assessment of skin color under natural light, and encourage care-seeking in preference over traditional treatments. Educational campaigns should be coupled with building capacity at the district hospital for bilirubin screening and phototherapy to respond to increased demand for treatment. Investment in these interventions and equipment, however, should be done cautiously because their potential efficacy and cost-benefits are not yet known. We have no information on the actual incidence of jaundice meeting American Academy of Pediatrics criteria for phototherapy [41] or the outcome of untreated cases, and thus cannot determine if this approach will prevent many cases of kernicterus. These interventions may lead to unnecessary laboratory screening and phototherapy which may burden limited resources. Further studies to evaluate outcomes of untreated, jaundiced infants compared to those treated with phototherapy may provide the needed data to support such interventions and determine the cost-benefit of widespread implementation of phototherapy at district levels nationwide. In the interim, on-going efforts to build capacity at provincial hospitals, which care for higher risk infants, should be supported as they have been associated with decreased referrals to the NHP for both jaundice and kernicterus [29].

\section{Conclusions}

Low maternal knowledge of jaundice, traditional beliefs and newborn care practices, and short hospital stays after birth with absence of routine newborn follow-up may prevent or delay recognition of jaundice, care-seeking, or treatment, and may account for the lower than expected frequency of phototherapy in the community. Although an education campaign to modify community care practices and traditional beliefs may improve care-seeking and providing laboratory and phototherapy capabilities at district hospitals could improve detection and treatment of hyperbilirubinemia, it is unclear whether the exchange transfusions and kernicterus cases that could be prevented would be worth the added financial burden on the healthcare system. Therefore, it would be important to obtain the data on the long-term outcomes of jaundiced infants in the community who are untreated compared to those who are treated, to determine if such costly community interventions could be justified.

\section{Additional files}

\section{Additional file 1: Hyperbilirubinemia Study Questionnaire. \\ Hyperbilirubinemia study questionnaire translated into English.}

Additional file 2: Bo cau hoi nghien cuu ve benh tang bilirubin tu do trong mau. Hyperbilirubinemia study questionnaire in Vietnamese.

\section{Abbreviations}

NHP: National Hospital of Pediatrics; HSPH: Hanoi School of Public Health.

\section{Competing interests}

The authors declare that they have no competing interests.

\section{Authors' contributions}

LTL conceptualized and designed the study, designed data collection instruments, trained data collectors, piloted initial questionnaires, conducted data analysis, and drafted the manuscript. JCP and TBN assisted with study design, revised data collection instruments, conducted data analysis, reviewed and revised the draft manuscript. BHT approved the design and implementation of the study, coordinated and supervised the data collection. VTL, TKD, and HTN designed data collection instruments, trained data collectors, piloted initial questionnaires, coordinated and supervised the data collection, and conducted data analysis. All authors read and approved the final manuscript.

\section{Acknowledgements}

We would like to thank the families of Chi Linh District for their participation, the staff of the Hanoi School of Public Health, and the following staff from CHILILAB for their assistance: Project coordinator - Trinh Kim Oanh; Research assistants- Pham Thi Mai, Nguyen Thi Luong, Bui Thi Ken, Bui Thi Hue, Hoang Thi Chinh, Luong Thi Thoi, Nguyen Thi Hong Phuong, Pham Thi Huong, Vu Thi Nguyen; Data entry - Vu Thuy Hang, Nguyen Thi Binh, Tran Thu Huyen, Dang Van Anh; Information technology - Pham Viet Cuong. This study was funded by the University of California Pacific Rim Research Program, project reference number 08-T-PRRP-02-0033.

\section{Author details}

${ }^{1}$ Department of Pediatrics, University of California, San Francisco, Box 0748, 533 Parnassus Ave, U585, San Francisco, CA 94143, USA. ${ }^{2}$ CHILILAB, Hanoi School of Public Health, 138 Giang Vo, Hanoi, Vietnam. ${ }^{3}$ Department of Epidemiology \& Biostatistics, University of California, San Francisco, Box 0560, 185 Berry Street W, Suite 5700, San Francisco, CA 94143, USA. 
Received: 29 April 2014 Accepted: 29 September 2014

Published: 14 October 2014

\section{References}

1. Maisels MJ: Neonatal hyperbilirubinemia and kernicterus - not gone but sometimes forgotten. Early Hum Dev 2009, 85(11):727-732.

2. Abu-Ekteish F, Daoud A, Rimawi H, Kakish K, Abu-Heija A: Neonatal exchange transfusion: a Jordanian experience. Ann Trop Paediatr 2000, 20(1):57-60.

3. Hendrickse RG: Aspects of tropical paediatrics. Trans R Soc Trop Med Hyg 1976, 70(4):268-273.

4. Ho NK: Neonatal jaundice in Asia. Baillieres Clin Haematol 1992, 5(1):131-142.

5. Jirapaet K: Thai healthy newborns have a higher risk. J Med Assoc Thai 2005, 88(9):1314-1318.

6. Narang A, Kumar P, Kumar R: Neonatal jaundice in very low birth weight babies. Indian J Pediatr 2001, 68(4):307-309.

7. Ogunlesi TA, Dedeke IO, Adekanmbi AF, Fetuga MB, Ogunfowora OB: The incidence and outcome of bilirubin encephalopathy in Nigeria: a bi-centre study. Niger J Med 2007, 16(4):354-359.

8. Olusanya BO, Akande AA, Emokpae A, Olowe SA: Infants with severe neonatal jaundice in Lagos, Nigeria: incidence, correlates and hearing screening outcomes. Trop Med Int Health 2009, 14(3):301-310.

9. Owa JA, Osinaike Al: Neonatal morbidity and mortality in Nigeria. Indian J Pediatr 1998, 65(3):441-449.

10. Salas AA, Mazzi E: Exchange transfusion in infants with extreme hyperbilirubinemia: an experience from a developing country. Acto Paediatr 2008, 97(6):754-758.

11. Sanpavat S: Exchange transfusion and its morbidity in ten-year period at King Chulalongkorn Hospital. J Med Assoc Thai 2005, 88(5):588-592.

12. Tikmani SS, Warraich HJ, Abbasi F, Rizvi A, Darmstadt GL, Zaidi AK: Incidence of neonatal hyperbilirubinemia: a population-based prospective study in Pakistan. Trop Med Int Health 2010, 15(5):502-507.

13. Olusanya BO: Letter to the editors: the burden of neonatal jaundice and sepsis in developing countries. Trop Med Int Health 2006, 11(3):381.

14. Slusher T, Zipursky A, Bhutani VK: A global need for affordable neonatal jaundice technologies. Semin Perinatol 2011, 35(3):185-191.

15. Khu DT, Le LT, Partridge JC: Characteristics of Newborns Admitted for Hyperbilirubinemia at a Tertiary Referral Hospital in Northern Vietnam. [Abstract], 2009 Pediatric Academic Societies Annual Meeting. Baltimore, MD: Pediatric Academic Societies; 2009. E-PAS2009:4600.7

16. Le LT, Partridge JC, Newman TB: Causes of Hyperbilirubinemia Leading to Exchange Transfusion at a National Referral Hospital in Northern Vietnam: a Preliminary Case Series. [Abstract], 2009 Pediatric Academic Societies Annual Meeting. Baltimore, MD: Pediatric Academic Societies; 2009. EPAS2009:2842.410

17. Tran BH, Nguyen HT, Ho HT, Pham CV, Le VT, Le AV: The Chi Linh health and demographic surveillance system (CHILILAB HDSS). Int J Epidemiol 2013, 42(3):750-757. doi: 10.1093/ije/dyt053.

18. Hanoi School of Public Health: Demographic and Epidemiologic Surveillance System in CHILILAB. Introduction and Research Findings 2004-2006. Nha Xuat Ban Y Hoc: Vietnam; 2008.

19. UNICEF: Vietnam Statistics. Available at: http://www.unicef.org/ infobycountry/vietnam_statistics.html. Access date: November 5, 2013.

20. Escobar GJ, Greene JD, Hula P, Kincannon E, Bischoff K, Gardner MN, Armstrong MA, France EK: Rehospitalisation after birth hospitalisation: patterns among infants of all gestations. Arch Dis Child 2005, 90(2):125-131.

21. Burgos AE, Schmitt SK, Stevenson DK, Phibbs CS: Readmission for neonatal jaundice in California, 1991-2000: trends and implications. Pediatrics 2008, 121(4):e868-e869.

22. Setia S, Villaveces A, Dhillon P, Meuller BA: Neonatal jaundice in Asian, white, and mixed-race infants. Arch Pediatr Adolesc Med 2002, 156(3):276-279.

23. Kuzniewicz MW, Escobar GJ, Newman TB: Impact of universal bilirubin screening on severe hyperbilirubinemia and phototherapy use. Pediatrics 2009, 124(4):1031-1039.

24. Eggert LD, Wiedmeier SE, Wilson J, Christensen RD: The effect of instituting a prehospital-discharge newborn bilirubin screening program in an 18-hospital system. Pediatrics 2006, 117(5):e855-e862.

25. Petersen JR, Okorodudu AO, Mohammad AA, Fernando A, Shattuck KE: Association of transcutaneous bilirubin testing in hospital with decreased readmission rate for hyperbilirubinemia. Clin Chem 2005, 51(3):540-544.

26. General Statistics Office of Vietnam: available at http://www.gso.gov.vn/ default_en.aspx?tabid=467\&idmid=3\&ltem|D=15663.
27. Schneider P: Breast milk jaundice in the newborn. JAMA 1986, 255:3270-3274

28. Gartner L: Breastfeeding and jaundice. J Perinatol 2001, 21:S25-S29.

29. Joe P, Moccia L, Tran C, Arnolda G, Tran T: National Training Program on Neonatal Jaundice Management and Prevention in Vietnam. [Abstract], 2012 Pediatric Academic Societies Annual Meeting. Boston, MA: Pediatric Academic Societies; 2012. E-PAS2012:3814.176

30. Danielsson N, Hoa D, Thang N, Vos T, Loughnan P: Intracranial haemorrhage due to late onset vitamin $\mathrm{K}$ deficiency bleeding in Hanoi province, Vietnam. Arch Dis Child Fetal Neonatal Ed 2004, 89(6):F546-F550.

31. Eriksson L, Nguyen TN, Dinh PH, Persson LA, Ewald U, Wallin L: Newborn care and knowledge translation-perceptions among primary healthcare staff in northern Vietnam. Implement Sci 2011, 6:29.

32. Boskabadi $H$, Maamouri G, Mafinejad S: The effect of traditional remedies (camel's thorn, flixweed and sugar water) on idiopathic neonatal jaundice. Iran J Pediatr 2011, 21(3):325-330.

33. Aydin D, Ciftci EK, Karatas H: Identification of traditional methods of newborn mothers regarding jaundice in Turkey. J Clin Nurs 2013, 23:524-530.

34. Oyebola DDO: Care of the neonate and management of neonatal jaundice as practised by Yoruba traditional healers of Nigeria. J Trop Pediatr 1983, 29(2):18-22

35. Choudhry UK: Traditional practices of women from India: pregnancy, childbirth, and newborn care. JOGNN 1997, 26:533-539.

36. Martinez AM, Khu DTK, Boo NY, Neou L, Saysanasongkham B, Partridge JC: Barriers to neonatal care in developing countries: parents' and providers' perceptions. J Paediatr Child Health 2012, 48:852-858.

37. Nguyen $\mathrm{H}$, Wang $\mathrm{W}$ : The effects of free government health insurance among small children-evidence from the free care for children under six policy in Vietnam. Int J Health Plann Mgmt 2013, 28:3-15. doi:10.1002/ hpm.2114.

38. Shieh M, Thompson C, Tra MPV, Linh VTT, Tediosi F, Merson L, Farrar JJ, Tuan HM, Viet HL, Tuyet PTN, Baker S: The policy of free healthcare for children under the age of 6 years in Vietnam: assessment of the uptake for children hospitalised with acute diarrhoea in Ho Chi Minh City. Tropical Med Int Health, 18:1444-1451. doi: 10.1111/tmi.12208.

39. Van Minh H, Kim Phuong NT, Saksena P, James CD, Xu K: Financial burden of household out-of pocket health expenditure in Vietnam: findings from the National Living Standard Survey 2002-2010. Soc Sci Med 2013, 96:258-263. doi: 10.1016/j.socscimed.2012.11.028. Epub 2012 Dec 1.

40. Malqvist M, Hoa DT, Thompsen S: Causes and determinants of inequity in maternal and child health in Vietnam. BMC Public Health 2012, 12:641. doi:10.1186/1471-2458-12-641.

41. American Academy of Pediatrics Subcommittee on Hyperbilirubinemia: Management of hyperbilirubinemia in the newborn infant 35 or more weeks of gestation. Pediatrics 2004, 114(1):297-316.

doi:10.1186/1471-2431-14-264

Cite this article as: Le et al.: Care practices and traditional beliefs related to neonatal jaundice in northern Vietnam: a population-based, cross-sectional descriptive study. BMC Pediatrics 2014 14:264.

\section{Submit your next manuscript to BioMed Central and take full advantage of:}

- Convenient online submission

- Thorough peer review

- No space constraints or color figure charges

- Immediate publication on acceptance

- Inclusion in PubMed, CAS, Scopus and Google Scholar

- Research which is freely available for redistribution 